\title{
May Thurner syndrome revealed by left calf 1 comenow venous claudication during running, a case report
}

Samuel Béliard ${ }^{1,2^{*}}$, Damien Feuvrier ${ }^{3,4}$, Emilie Ducroux ${ }^{5}$ and Lucie Salomon du Mont ${ }^{5,6}$

\begin{abstract}
Background: May Thurner syndrome is relatively unknown to physicians, its management is well standardized and the outcomes of treatment are satisfactory in the short to medium term.

Case presentation: We report the case of a patient who suffered from venous claudication during running which impaired their quality of life, decreased their athletic performance and resulted in a career change. May Thurner syndrome diagnosis was made after extensive hemodynamic analysis of a lower limb venous duplex ultrasound scan. This diagnosis was later confirmed by imaging. Subsequent endovascular care provided rapid and sustained clinical improvement.
\end{abstract}

Conclusion: The main difficulties with the May Thurner syndrome are to think about it and know how to look for it; indeed the misdiagnosis time can be long. When diagnosis is made, treatment could be easy and effective.

Keywords: May Thurner syndrome, Venous compression, Venous claudication, Post thrombotic syndrome, Case report

\section{Background}

The most commonly proposed aetiologies of calf pain during physical exercise are muscular (muscle injury, compartment syndrome), rheumatologic (chronic bone micro traumatic pathology, projected joint pain), neurological (lumbar compression syndrome, neuropathy device) or arterial (claudication). Chronic venous disease that is related or not with a post thrombotic syndrome, could be another explanation but this is not often explored and therefore not often suggested as an aetiology. Symptoms of venous claudication during physical exercise involve deep pain, first dull, then intense and constrictive, in the calf or thigh, culminating in functional impairment. Unlike arterial claudication, these sensations don't diminish after effort, but dissipate when the patient assumes a position that enhances venous drainage position [1]. Often this involves elevating the

\footnotetext{
*Correspondence: samuel.beliard@gmail.com

${ }^{1}$ PEPITE EA4267, Platform Exercise Performance Health Innovation (EPHI),

University Bourgogne Franche-Comté, F-25000 Besançon, France

${ }^{2}$ Cardiology, Angiology, Anticoagulation Clinic, Hôpital Louis Pasteur, Dole

39100, France

Full list of author information is available at the end of the article
}

lower limbs to $45^{\circ}$ relative to the horizontal when in the supine position [2].

Here we report a clinical case in which investigative semiology analysis and hemodynamic exploration for venous claudication after exercise helped to diagnose May Thurner syndrome (MTS) in a patient, following a lengthy period of misdiagnosis. We obtained the written agreement of the subject involved in the clinical case before writing this article. Then the subject signed the declaration for the 'Consent for publication'.

\section{Case presentation Context}

A 25-year-old man was referred to vascular medicine clinic because of pain in the left calf while running, which had been occurring for the past 4 years.

This patient practiced almost daily physical activity that involved both combative and running (over $8 \mathrm{~h}$ per week), and he competed at a regional level (with a personal best of running of $36 \mathrm{~min} 12 \mathrm{~s} / 10000 \mathrm{~m}$ ). In 2012, the patient had reported left calf pain when running, forcing him to stop. He described a calf swelling sensation that gradually increased with the intensity of running. While in the past 
he could easily run $15-20 \mathrm{~km}$, the patient reported at that date that he could not run more than $2 \mathrm{~km}$ before having to stop. After stopping, the pain was deep and persisted for several minutes; it was also associated with swelling of the calf. This pain had led him to change his occupation to a less physically demanding job (military officer in the past, and now security officer). The consequences were a weight gain of $8 \mathrm{~kg}$, and a cessation of all physical activity (running, fight sports). The patient also reported a loss of self-esteem.

\section{History of the disease}

Over a period of 4 years, the patient was seen by two general physicians, a rheumatologist, a neurologist, a sports physician and a vascular physician. Many explorations were carried out (spinal and pelvic $\mathrm{x}$-ray, pelvic and lumbar spine scan, venous duplex scan, arterial duplex scan, and electromyography), all of which revealed no sign of dysfunction. The sports physician raised the possibility of diagnosis of a compartment syndrome, but the patient refused to submit to investigation of intramuscular pressure taken at rest and in immediately post exercise. Different therapies were proposed, including anti-inflammatory drugs, paracetamol and compression stockings (Class 2).

The patient interview revealed that a proximal deep vein thrombosis DVT (thrombosis in the iliac, femoral and popliteal veins) of the left lower limb had been diagnosed in 2012 and treated for 6 months by direct oral anticoagulant therapy (Rivaroxaban, Xarelto $20 \mathrm{mg}$ per day) combined with compression stockings french class 3 worn $(20-36 \mathrm{mmHg})$ for 6 months and then class 2 compression socks $(15-20 \mathrm{mmHg})$ thereafter. This episode of DVT occurred spontaneously without major or minor contributing factors. There was no family history of venous thromboembolism disease. Clinical and laboratory tests had found no neoplasia. The biological thrombophilia test at distance of anticoagulation was negative.

\section{First consultation}

\section{Physical examination}

The patient was $1.78 \mathrm{~m}$ and $79 \mathrm{~kg}$ (body mass index $=24.9 \mathrm{~kg} / \mathrm{m}^{2}$ ). He was afebrile, and his brachial blood pressure was $120 / 70 \mathrm{mmHg}$. Upon examination the legs were hot and there was no trophic disorder. There was a difference in the circumference of the calves (left calf $2 \mathrm{~cm}>$ right calf). There were no visible or palpable varicose veins. Peripheral pulses were present and there was no sign of Lassegue. Palpation of the major lower limb joints (ankles, knees, hips) was not painful. Calves were flexible, painless, with good trophicity. No lymphadenopathy was found and no local inflammatory signs. When examined by auscultation, there were no vascular sounds along the vascular axes.

\section{Vascular duplex scan exploration}

All Doppler ultrasound measurements were performed with a high-resolution ultrasound machine (Affiniti 70, Philips, Amsterdam, The Netherlands). The deep venous system was free and compressible when compressed by the ultrasound probe at calf level (posterior tibial veins, peroneal, gastrocnemius and soleus), at femoral popliteal level (popliteal veins, femoral and common femoral) and at ilio-cava level with no sign of recent deep vein thrombosis. There was wall thickening at the left common femoral vein CFV (anterior posterior diameter APD under compression $=3.9 \mathrm{~mm}$ ) and at the left external iliac vein (APD under compression $=3.6 \mathrm{~mm}$ ); this finding had already been highlighted when vascular physician examined the patient in 2013.

The Doppler examination showed a clear asymmetry of the respiratory modulations of blood velocity between right and left CFV. In the left CVT, respiratory modulations were almost absent and blood volume flow was not as high as on the right side. We found a reflux into the left internal iliac vein and dilation of the left gonadal vein. While standing, there was no significant deep venous reflux ( $>1 \mathrm{~s}$ ) at the popliteal vein (functional venous valves). The superficial venous system (great and small saphenous veins) was compressible and continent.

The diagnostic hypothesis of MTS was issued at the end of this first consultation, taking into account the following clinical and hemodynamic arguments:

History of the left proximal DVT without predisposing factor.

Symptoms of left calf venous claudication due to effort (+/- associated with unilateral edema reported by the patient).

Asymmetry respiratory modulation and venous blood volume flow at the left proximal deep vein (as a result of a downstream obstacle).

Additional morphological exploration was requested computed tomography angiography (CTA) and a surgical opinion was recommended and requested.

\section{Support \\ CTA acquisition with venous phase}

The CTA revealed compression of the left common iliac vein (CIV) between the right common iliac artery (CIA) and lumbar spine (Fig. 1) and intraluminal spurs. There was also dissimilar venous systems collatorally with that was more highly developed on the left iliac axis relative to the right iliac axis, reflecting the need to create a system of substitution. 


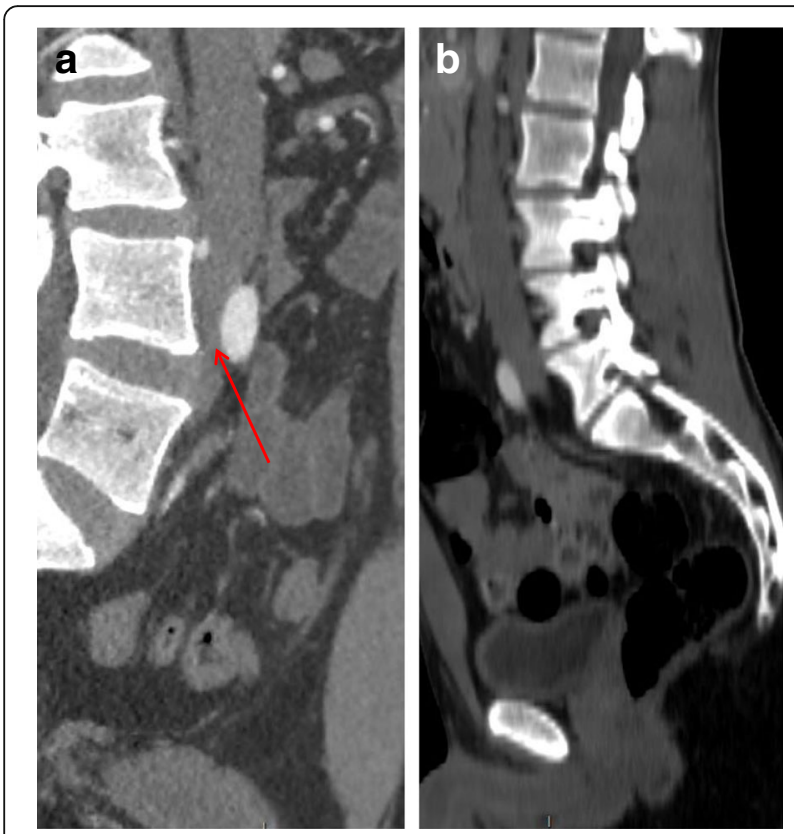

Fig. 1 computed tomography angiography. a. Compression of the left common iliac vein between the right common iliac artery and lumbar spine. b. Normal left common iliac vein

\section{Surgical procedure}

In this context of symptomatic MTS with compatible imaging, venography was performed in order to confirm the diagnosis and to treat the MTS at the same time. Venography showed patency of the left venous axis iliac featuring endoluminal spurs and a footprint at the terminal portion of the iliac vein (Fig. 2).

Endovascular support was carried out with introduction of two Wallstent endo prostheses (Boston Scientific) into the common iliac and external iliac veins, associated

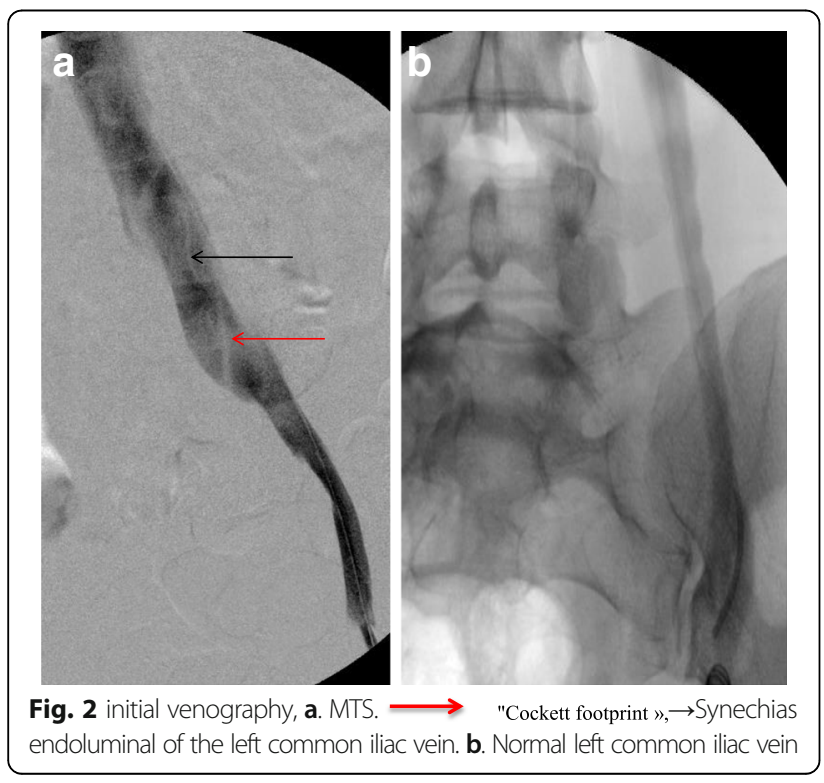

with angioplasty intra stent to modulate the different areas of overlap, the diameters and lengths to achieve a harmonious assembly. The phlebographic control carried out at the end of the procedure was satisfactory.

\section{Results at 3 and 6 months}

At 3 and 6 months, the patient reported an improvement in symptoms. The patient restarted running, and initially venous claudication was not felt and the patient was once more able to run more than $10 \mathrm{~km}$. He currently wears a compression class III especially during physical activity, as advised.

Angiographic assessment found normal stent patency at the iliac vein, with symmetrical respiratory modulations. It was also decided to carry out a duplex ultrasound scan at 3 months. At this scanning session the stents were in place and permeable. Pharmacological treatment in the form of an anti platelet (Clopidogrel $75 \mathrm{mg}$ ) was prescribed.

\section{Discussion}

With this study, the diagnostic criteria of MTS by imaging (CTA and venography) and the subsequent therapeutic management are now well described and outcomes suggest excellent recovery.

The difficulty in diagnosis and treatment of MTS is simply to consider it a possibility before overt clinical presentation and then to carry out the appropriate explorations. For this, the vascular physician should be primarily a clinician and should strive to conduct the investigation via a directed examination and a search for non-specific clinical signs. Then during functional exploration, the physician must consider the hemodynamics and not base their assessment on imaging alone. Indeed, the compression of the iliac vein is not detectable by duplex scan and in the absence of acute proximal deep vein thrombosis (external iliac or at the femoral vein), the physician can miss a diagnosis of MTS. Respiratory modulations are spontaneous rhythmic flow which reflect the effects of pulmonary ventilation on the variability of venous flow. During inspiration, diaphragmatic contraction increases the abdominal pressure, and reduces the flow of the lower limb veins that are dependent on the inferior vena cava system. The opposite phenomenon is observed during expiration [3]. If a hemodynamic exploration includes analysis of respiratory modulations of the proximal venous flow (within the external iliac vein and / or the femoral vein), accompanied by dynamic maneuvers (Valsalva, venous blood volume flow), the presence of asymmetry between the two sides would point quite clearly to a downstream stenosis syndrome (the obliteration table, or compression table is to be explored in static imaging thereafter).

In clinical practice, diagnosis and treatment of MTS presents several difficulties. 
- Physicians do not clearly understand the aetiological in its entirety. The misdiagnosis time can be long, a study of 58 patients with MTS revealed a median time of 59 +/15 months (range: 0-376 months) before the diagnosis [4]. The clinical case reported here confirms this problem, with 4 years before obtaining suitable support. - In the case of clinical suspicion, the difficulty is to establish the diagnosis. It is important to differentiate a "Cockett footprint "(compression of the vein by the artery on a static image without endoluminal spurs) or "Cockett postural syndrome "(compression-related hyperlordosis) with specific MTS which associating compression of the left iliac vein by the right iliac artery, and the presence of endoluminal spurs within the iliac vein [5]. A high frequency of this anatomical feature is found in many asymptomatic patients both on autopsy analysis (22\% of 430 bodies) [6] and/or imaging [7]. Kibbe et al. [7] demonstrate, on a CTA series of 50 consecutive patients evaluated for emergency abdominal pain, without any venous symptoms, a reduction $>50 \%$ in diameter of the left CIV in a quarter of the patients, and $>25 \%$ in two thirds of patients. Similarly, a study from Narayan et al. [8] shows that a compression $<70 \%$ does not increase the relative risk of DVT [8], while a compression $>70 \%$ of the vein increases the risk. The presence of a Cockett footprint on CTA [8] or angiography combined with magnetic resonance imaging [9] of the iliac vein to the iliac artery is not sufficient to confirm the diagnosis.

The differential diagnostic process before a calf venous claudication, should be structured to consider a diagnosis of MTS (Fig. 3). Diagnosis of MTS should thus be established based upon a set of arguments [10]:

- Medical history: A history of venous thromboembolism, acute symptoms (left proximal DVT), chronic symptoms (post thrombotic syndrome PTS, recurrent DVT, venous claudication, unilateral varicocele [11]). PTS is defined by the presence of

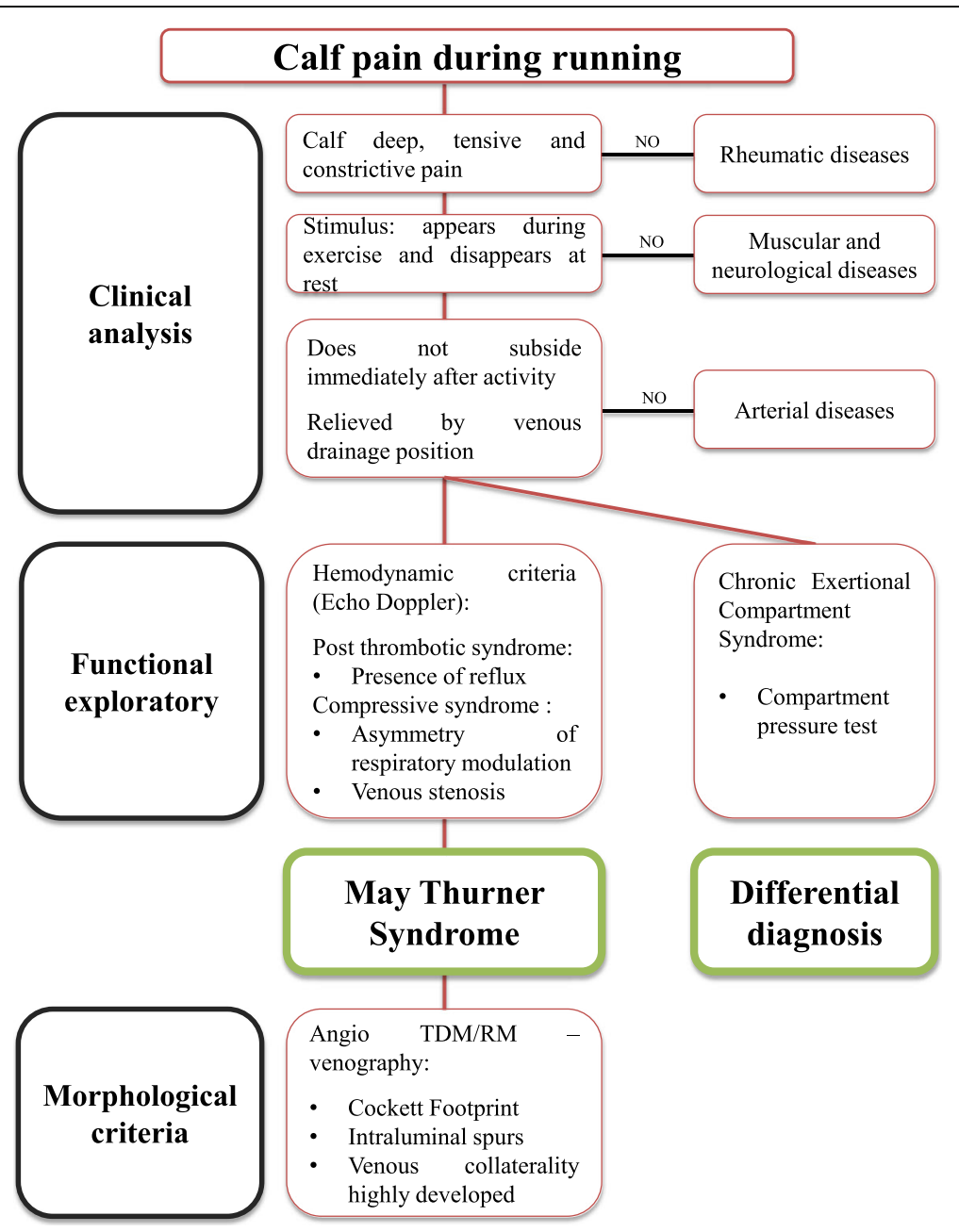

Fig. 3 Decision tree: reasoning before an exertional leg pain 
symptoms (pain, heaviness, pruritus) and/or chronic venous signs (C1 - C6 of CEAP (Clinical, Etiologic, Anatomic, Pathophysiologic) classification: telangiectasia, reticular veins, varicose veins, edema pigmentation, eczema, lipodermatosclerosis, white atrophy, venous ulcer) secondary to lower limb deep venous thrombosis [12].

- Clinical: With MTS, pain is mainly located in the calf. This pain is deep and constrictive. It appears during exercise and disappears at rest. Unlike arterial claudication, MTS pain does not yield immediately after activity and is relieved by assuming a venous drainage position. All characteristics of this pain often mirror those of chronic exertional compartment syndrome [13]. To differentiate both entities, a compartment pressure test must be carried out. Sometimes, more than one aetiology for exertional leg pain can coexist in an athlete [14].

- Hemodynamic: Duplex ultrasound scan [15] (PTS with analysis of the reflux, compressive syndrome with asymmetry respiratory modulations, venous stenosis), +/- plethysmography (evaluation of reflux) +/intravenous ultrasound [16] (intra luminal damaged, pretreatment evaluation) needs to be performed and must involve specific evaluation of the respiratory modulation of venous flow bilaterally.

- Morphological [17] (CTA +/- angio MR +/venography): Evidence of compression, more highly developed collatorally, the presence or absence of thrombosis and intra luminal spurs.

If MTS is confirmed, therapeutic management is now well defined [18], and is relatively simple and minimally invasive. It combines medical treatment [4] (walking, compression device class III) and endovascular management [19] (angioplasty stenting). This support leads to a significant improvement in symptoms and quality of life [20], and is associated with high low long-term patency rates $[4,10]$. The main risk of this therapeutic management is recurrence. However, medium- and long-term patency have been evaluated and are highly in favor of treatment [4] with primary patency rates of $74.1 \%$ at 1 year (SE, 6.3\%) and $38.1 \%$ at 60 months (SE, 12.4\%); and secondary patency rates of $85.8 \%$ at 1 year $(\mathrm{SE}, 5.0 \%)$ and $73.8 \%$ at 60 months (SE, 9.7\%). There is no consensus concerning the duration of platelet therapy after the surgical procedure. In our practice, we continue this treatment after the first year by re-evaluating the risk benefit ratio.

\section{Conclusion}

In conclusion, diagnostic error before a MTS, reported in the literature and found in this clinical case could be reduced by changing two factors. First a better understanding of this disease and of venous claudication indices by physicians is required (general, vascular and sports medicine physicians). Second a systematic hemodynamic analysis by the vascular physician of the venous vasculature lower limbs is needed. Compliance with this latter element will highlight asymmetry of venous flow to the proximal lower limb. A report of the French Society for Vascular Medicine [21] recommends an exploration of the iliac cave veins with analysis of respiratory modulation and examination of venous blood volume flow. Laroche [22] recalled the importance of this comprehensive review of the venous system at the 50th congress of the French college of vascular disease [22].

\section{Practical implications}

- The May Thurner Syndrome is not well known, which can cause a long delay between the onset of symptoms and treatment.

- The diagnostic criteria, before a calf venous claudication, should be structured in order to reach the diagnosis of May Thurner Syndrome. This diagnosis is based on a set of clinical, hemodynamic and morphological criteria.

- When May Thurner Syndrome is diagnosed, stenting supported by angioplasty is simple, minimally invasive, and obtains excellent results both in terms of eliminating symptoms and improving quality of life for the patient.

\author{
Acknowledgements \\ The authors would like to thank the subject for this agreement. We also \\ thank D. Clay and M. Rakobowchuk for technical assistance and translation. \\ The authors thank Simon Rinckenbach (Department of Vascular Surgery, \\ University Hospital Besancon, France) for general supervision of the research \\ group. We thank AMDAC (association médicale doloise pour le bon usage \\ des anticoaguilant) for its help. \\ Funding \\ Not applicable. \\ Availability of data and materials \\ Not applicable.

\begin{abstract}
Authors' contributions
Study conception and design: SB, FD. Physical examination, Vascular Echo of data: ED, LSDM. Writing of the draft manuscript: All Final approval of manuscript for submission. All authors read and approved the final manuscript.
\end{abstract} \\ Doppler Exploration: SB. Surgical procedure and contribution to acquisition
}

Ethics approval and consent to participate Not applicable

Consent for publication

We obtained the written agreement of the subject involved in the clinical case before writing this article. Then the subject signed the declaration for the 'Consent for publication'.

Competing interests

All authors disclose any financial and personal relationships with other people organizations that could inappropriately influence their work. 


\section{Publisher's Note}

Springer Nature remains neutral with regard to jurisdictional claims in published maps and institutional affiliations.

\section{Author details}

'PEPITE EA4267, Platform Exercise Performance Health Innovation (EPHI), University Bourgogne Franche-Comté, F-25000 Besançon, France. ${ }^{2}$ Cardiology, Angiology, Anticoagulation Clinic, Hôpital Louis Pasteur, Dole 39100, France. ${ }^{3}$ Department of orthopedic and trauma surgery, plastic surgery, plastic and reconstructive, hand surgery, University Hospital , CHUR Jean Minjoz, 25000 Besançon, France. ${ }^{4}$ Laboratory of Anatomy, Faculty of Medical and Pharmaceutical Sciences, 20 rue Ambroise Paré, 25030 Besançon, France. ${ }^{5}$ Vascular Surgery, Vascular Medicine, University Hospital, CHUR Jean Minjoz, 25000 Besançon, France. ${ }^{6}$ EA. 3920, Unversity of Franche-Comté, Besançon, France.

\section{Received: 25 October 2016 Accepted: 25 January 2018}

\section{Published online: 02 February 2018}

\section{References}

1. Becker F. Dictionary of vascular medicine terms: venous disease (A-O) ; Vol. 2. venous disease (P-Z). Elsevier: Masson; 2006.

2. Le Roux P, Planchon B. Recherche de la position optimale de drainage veineux des membres inférieurs par pléthysmographie occlusive. Ann Kinésithérapie. 1994;21(1):33-6.

3. Laroche J-P. Les veines respirent! Sang Thrombose Vaisseaux. 2012;24(3): 143-5.

4. Knipp BS, Ferguson E, Williams DM, Dasika NJ, Cwikiel W, Henke PK, Wakefield TW. Factors associated with outcome after interventional treatment of symptomatic iliac vein compression syndrome. J Vasc Surg. 2007:46(4):743-9.

5. Laroche J-P, Becker J-F, Dadon M, Brisot D, Coupé M, Khau Van Kien A, Böge $\mathrm{G}$, et al. Le syndrome de Cockett : mythe ou réalité ? J Mal Vasc. 2011 36(2):74-5.

6. May $R$, Thurner J. The cause of the predominantly Sinistral occurrence of thrombosis of the pelvic veins. Angiology. 1957;8(5):419-27.

7. Kibbe MR, Michael U, Lee Goodwin A, Eskandari M, Yao J, Matsumura J. Iliac vein compression in an asymptomatic patient population. J Vasc Surg. 2004 39(5):937-43.

8. Narayan A, Eng J, Carmi L, McGrane S, Muneeb A, Richey Sharrett A, Streiff M, Coresh J, Powe N, Hong K. lliac vein compression as risk factor for leftversus right-sided deep venous thrombosis: case-control study. Radiology. 2012;265(3):949-57.

9. McDermott S, Oliveira G, Ergül E, Brazeau N, Wicky S, Oklu R. May-Thurner syndrome: can it be diagnosed by a single MR Venography study? Diagn Interv Radiol (Ankara, Turkey). 2013;19(1):44-8. https://doi.org/10.4261/13053825.DIR.5939-12.1.

10. Brinegar KN, Sheth RA, Khademhosseini A, Bautista J, Oklu R. Iliac vein compression syndrome: clinical, imaging and pathologic findings. World J Radiol. 2015:7(11):375-81.

11. Bomalaski MD, Mills JL, Argueso LR, Fujitani RM, Sago AL, Joseph AE. Iliac vein compression syndrome: an unusual cause of Varicocele. J Vasc Surg. 1993;18(6):1064-8

12. Galanaud J-P. Syndrome post-thrombotique selon les recommandations de I'American Heart Association 2014. J Mal Vasc, 14e Congrès de la Société Française de Médecine Vasculaire. 2015;40(5):300.

13. Joubert SV, Duarte MA. Chronic Exertional compartment syndrome in a healthy young man. J Chiropractic Med. 2016;15(2):139-44. https://doi.org/ 10.1016/j.jcm.2016.04.007.

14. Garlanger $\mathrm{KL}$, Jelsing EJ, Finnoff JT. External iliac artery vasospasm in an elite female runner. Sports Health. 2017:9(1):87-90.

15. Labropoulos N, Borge M, Pierce K, Pappas PJ. Criteria for defining significant central vein Stenosis with duplex ultrasound. J Vasc Surg. 2007:46(1):101-7.

16. Ahmed HK, Hagspiel KD. Intravascular Ultrasonographic findings in mayThurner syndrome (iliac vein compression syndrome). J Ultrasound Med. 2001:20(3):251-6.

17. Donatella N, Marcello BU, Gaetano V, Massimo P, Massimo M, Giancarlo B. What the young physician should know about may-Thurner syndrome. In: Translational Medicine @ UniSa 12 (août); 2015. p. 19-28.

18. Dadon M. Le syndrome de Cockett. J Mal Vasc, 9e Congrès de la Sociéte Française de Médecine Vasculaire. 2010;35(5):305-6.
19. Jenkins JS, Michael P. Deep venous thrombosis: an Interventionalist's approach. Ochsner J. 2014;14(4):633-40.

20. Raju S, Neglén P. Percutaneous Recanalization of Total occlusions of the iliac vein. J Vasc Surg. 2009:50(2):360-8.

21. Auvert J-F, Chleir F, Coppé G, Hamel-Desnos C, Moraglia L, Pichot O, SFMV. Quality standards for ultrasound assessment of the superficial venous system of the lower limbs. Report of the French Society for Vascular Medicine. J Mal Vasc. 2014;39(1):26-46.

22. Laroche J-P. L'art de l'écho-Doppler veineux en 2016. J Mal Vasc, 50e congrès de Collège Français de Pathologie Vasculaire. 2016;41(2):118-9.

\section{Submit your next manuscript to BioMed Central and we will help you at every step:}

- We accept pre-submission inquiries

- Our selector tool helps you to find the most relevant journal

- We provide round the clock customer support

- Convenient online submission

- Thorough peer review

- Inclusion in PubMed and all major indexing services

- Maximum visibility for your research

Submit your manuscript at www.biomedcentral.com/submit
Biomed Central 